\title{
Probiotic induce macrophage cytokine production via activation of STAT-3 pathway
}

\author{
Neama Y, Habil \\ Medical Technology Institute, Medical Technical University, Baghdad, Iraq
}

Email address:

neamahabil@gmail.com (N. Y, Habil)

To cite this article:

Neama Y, Habil. Probiotic Induce Macrophage Cytokine Production Via Activation of STAT-3 Pathway. Automation, Control and Intelligent Systems. Special Issue: Artificial Nano Sensory System. Vol. 3, No. 2-1, 2015, pp. 1-7. doi: 10.11648/j.acis.s.2015030201.11

\begin{abstract}
Macrophages are mononuclear phagocytes generated from monocyte emigrated from blood circulation. Macrophages mediated the innate and adaptive immunity through different routes, and cytokine production is one of these routes. Signal transducer and activators of transcription (STATs) are cytoplasmic transcription factors that are key mediators of cytokine and growth factor signalling pathways. STAT-3 is implicated in macrophage cytokine signalling and production. It's well reported that the microbiota is very important as it primes the immune system for the antigens encountered later in life. Probiotics defined as 'Live microorganisms which when administered in adequate amounts confer a health benefit on the host. Therefore, the aim of this project was to answer the question whether probiotics induced cytokine production via activation of STAT-3 signalling pathway.Results showed that probiotic Lactobacillus casie strain Shirota was successfully induced cytokine production via activation of STAT-3 by anti-inflammatory macrophages induced by TNF- $\alpha$. The findings of this study will open new strategy to modulate the immune response by probiotic bacterialeading to treat the diseasesthat related with irregular cytokine production.
\end{abstract}

Keywords: Macrophages, Probiotics, Cytokines, STAT-3

\section{Introduction}

Historically macrophages are one of the antigen presenting cells (APCs) found in the lamina propria of the gut that can processing and presenting of antigens to $\mathrm{T}$ lymphocyteafter recognition of microbesleading to induce appropriate immune responses in response to microbial infection which will be determined by $\mathrm{T}$ cells . Macrophages involve a critical component of innate immunity; they play vital roles in eradicating pathogenic microbes and keeping tissue homeostasis. They express non-specific esterase, lysosomal hydrolases and ectoenzymes, resulting in contributing to nonspecific uptake of particular materials (Hume, 2006). Macrophages also express an array of receptors for the $\mathrm{Fc}$ portion of immunoglobulin (Ig) and complement components.

In adaptive immunity, macrophages have the excessive competence to present antigens to $\mathrm{T}$ cells after phagocytise, kill, degrade microorganism materials, and process antigens for presentation to $\mathrm{T}$ cells on MHCII molecule; ultimately, the expression of molecules such as MHC 1 and MHC 11 and co-stimulatory molecules, B7-1 (CD80) and B7-2(CD86) by macrophages due it to involve in antigen processing and presentation leading to direct adaptive immunity (Paolillo et al., 2009). However, macrophages are able to regulate immune response via secreting various cytokines.

At the early stage of infection, the macrophages were recruited to the infected site to engulf the microbes, and when macrophages were activated after bacterial recognition by TLRs consequently they were produced highly level of proinflammatory cytokines such as IL- $1 \beta$, TNF- $\alpha$, IL-8, IL-6 and chemokineswhich recruits more macrophages and other immune cells e.g. neutrophils and basophils, these immune cells were collaborated together to eliminate infection and cause acute inflammation. On the other hand, at the late stage of infection, the macrophages exhibit another phenotype that contributes to resolution of inflammation and tissue repair through production of anti-inflammatory cytokines. Therefore, macrophages are exhibiting a wide range of functions which are both determined by differentiation and activation factors come upon by the cells in response to pathogenic infection.

Generally, macrophages classified as classically activated 
M1 pro-inflammatory macrophage and alternatively antiinflammatory M2 macrophages (Mantovani et al., 2007). Classically activated M1 pro-inflammatory macrophage demonstrates Th1 phenotype promoting inflammation and destructive effects of tissues, whilst alternatively M2 antiinflammatory/regulatory macrophages demonstrate a Th2 phenotype promoting constructive effects of the tissues and resolve the inflammation (Mantovani et al., 2007, Mosser and Edwards, 2008); both of the phenotypes are important in both innate and adaptive immunity. The diversity and plasticity of macrophage depend on many factors such as the stimuli represented by tissue environment and cytokine produced by other immune cells such as $\mathrm{T}$ helper cells (Haller et al., 2000, Gordon, 2003). Granulocyte macrophage colony stimulating factor (GM-CSF) and macrophage colony stimulating factor (M-CSF) have been concerned in the differentiation of M1 and M2-like macrophages respectively (Verreck et al., 2004). Based on an evidenced,Foey.,(2012) reported that classically activated M1 macrophage cells differentiation are requires priming by IFN $\gamma$ plus triggering with microbial LPS ,or GM-CSF, these events are followed by dramatic alteration in the secretory profile of the cells and the cells become the phenotype be like IL-12 ${ }^{\text {hi }}$, IL-23 ${ }^{\text {hi }}$, IL$10^{\text {lo }}, \mathrm{TNF}-\alpha$ hi, CD14+, CD86+, iNOS, STAT-1+, and professional in degradation extracellular components such as collagen, elastin, and fibrinogen by producing proteolytic enzymes including matrix metalloproteinase MMP-1, -2, -7, 9, and -12(Duffield, 2003). Among the pro-inflammatory cytokines produced by classically activated M1macrophages are TNF- $\alpha$, IL- 6 , IL- 8 , and IL- $1 \beta$ which have a crucial role in chemo attractant for neutrophils, immature dendritic cells, natural killer cells, and activated T cells. For alternatively M2 macrophage cells differentiation and activation does not need any priming by LPS, and IL-4, IL-13, IL-10, TGF- $\beta$, M-CSF, vitamin $\mathrm{D}_{3}$ and immune complexes can act as sufficient stimuli to achieve this goal (Gordon, 2003). Cytokines are mainly released by macrophages whether M1 or M2., however, the production of these molecules is vital for host defence and track the adaptive immune system. The uncontrolled way of these mediators release by macrophage cells have significant roles of collateral injure on the host micro-environment that control inflammatory responses.

Recently, one member of the Stat family (STAT-3), has appeared as a negative regulator of inflammatory responses(Cheng et al., 2003). These transcriptional factors are latent in themacrophage cytoplasm until they are activated by extracellular signalling proteins (mainly cytokines and growth factors) that bind to specific cellsurface receptors. These extracellular-signalling proteins can activate various tyrosine kinases in the cell that phosphorylate STAT proteins. The activated STAT proteins accumulate in the nucleus to drive transcription. The duration and degree of gene activation are under strictly regulated by a series of negative acting proteins. There are several types of negative regulators of STAT proteins in the cell cytoplasm such as suppressors of cytokine signalling (SOCS proteins) which block further STAT activation in the cell cytoplasm
(Bromberg, 2002 ).STAT-3 signalling plays a critical role in the induction of antigen-specific $\mathrm{T}$ cell tolerance. Targeted disruption of STAT-3 signalling in APCs resulted in priming of antigen-specific $\mathrm{CD}^{+} \mathrm{T}$ cells. Cheng et al., (2003) demonstrated that manipulation of STAT-3 signalling in either direction (blockade or stimulation) influenced immune responses explaining that STAT-3 have a role in the immune activation versus immune tolerance, which critical decision with profound implications in autoimmunity, transplantation, and cancer. Constitutively active forms of STAT-3 increase transcription of anti-apoptotic and cell-cycle-progression genes such as BCLXL, Cyclin-D1, Cyclin-D2, Cyclin-D3, and Cyclin-A, Pim1, c-Myc and p19 (Donnelly et al., 1999). Takeda et al., (1999) demonstrated that the disruption of the STAT-3 gene in macrophages increased production of inflammatory cytokines such as TNF- $\alpha$, IL-1, IFN $\gamma$, and IL-6 and suppressed IL-10 leading to develop chronic colitis, explaining that STAT-3 plays a critical role in the deactivation of macrophages mainly exerted by IL-10, these observation supported the concept that macrophages have a role in maintaining intestinal homeostasis through the expression of IL-10 by activation of STAT-3 (Matsukawa et al., 2005). However, it is important to note that the STAT-3 signalling pathway is shared by other cytokines such as IL6through gp130 a common signal transducer for the IL-6 cytokine (Fukada et al., 1996), which has been shown to be vital for intestinal epithelial homeostasis (Yang et al., 2007). However, overproduction of IL-6 mediated epithelial cell cancer. Grivennikov et al., (2009) reported that STAT-3 have been mediated initiating tumour of macrophage cells through the proliferative and survival effects of IL-6.

Probiotic bacteria are friendly bacteria that have important roles in modulating the immune system and confer health benefits prophylactically to many of diseases such as allergies, inflammatory pathologies and cancer(Winkler et al., 2007, Dotan and Rachmilewitz, 2005). However, these immunomodulation roles of probiotic are partly attributable to immune cell phenotype being studied, its environment and the strain of probiotic being used. Current understanding of probiotic modulations of such important gut mucosal cells like macrophages mediated immune responses relevant to mucosal homeostatic and inflammatory pathological environments is relatively poorly understood. Therefore, the current study was performed to evaluate the potential effects of probiotic on modulation of cytokine production via such a specific mechanism of cell signalling involve modulation of transcriptional factor activation of STAT-3 pathway.

\section{Materials and Methods}

\subsection{Isolation and Culture of Peripheral Blood Monocytes and Macrophage Induction}

Peripheral blood was obtained from healthy volunteers by venipuncture, using heparin to prevent coagulation in accordance with approved ethical guidelines. Blood was diluted 1:1 in un-supplemented media $(\alpha-\mathrm{MEM})$. Based on 
methods ofBuechler et al. (2000), mononuclear cells were isolated by centrifuging $15 \mathrm{ml}$ of $\alpha$ MEMblood suspension over $25 \mathrm{ml}$ of Histopaque-1077 (Sigma-Aldrich, UK), at 700 $\times \mathrm{g}$ for $30 \mathrm{~min}$ at $4^{\circ} \mathrm{C}$. The buffy layer containing monocytes was removed and washed in $10 \mathrm{ml}$ of non-supplemented $\alpha$ MEM then centrifuged at $400 \times \mathrm{g}$ for $10 \mathrm{~min}$ at $4{ }^{\circ} \mathrm{C}$. The cell pellet was re-suspended in culture medium containing $10 \%$ FCS and redcells lysed using a $10 \%$ acetic acid solution. For the induction of macrophage formation, $1 \times 10^{4}$ PBMCs were cultured in 96 well plates containing $\alpha$-MEM supplemented with $50 \mathrm{ng} / \mathrm{ml} \mathrm{M-CSF}$ for three days at $37^{\circ} \mathrm{C}$ in a humidified atmosphere of $5 \% \mathrm{CO}_{2}$ to differentiate monocyte cells to the anti-inflammatory M2 macrophage cells.

\subsection{Protein Blotting}

After resolving the proteins by SDS-PAGE, gels were transferred to polyvinylidene fluoride (PVDF) membranes using an electro blotter system (Criterion blotter, BIO-RAD, UK). For detection phosphorylated STAT-3 (pSTAT-3) protein (Tyr 705), western blotting (WB) technique was used, and developing colour for protein detection was performed by using ECL-Plus to detect peroxidase activity from HRPconjugated antibody.

\subsection{Bacterial Culture and Preparation of Heat Killed Bacteria}

Lactobacillus casei strain Shirota $(\mathrm{LcS})$ probiotic bacteria were obtained from commercially available Yakult drink (Yakult, UK), and Lactobacillus fermentum strain MS15 (LF) was isolated from the crop of a chicken (Savvidou, 2009) and obtained from internal microbiology stocks at the University of Plymouth (UK). Probiotic bacterial cell culture and preparation of heat killed bacteria wereperformed according to Habil et al. (2012).

\subsection{Activation of Macrophage Cytokine Production and STAT-3 Activation}

The anti-inflammatory M2 macrophages were stimulated with1 $0 \mathrm{ng} / \mathrm{ml}$ of TNF- $\alpha$ or $5 \mathrm{ng} / \mathrm{ml} \mathrm{IL-1} \beta$ for 6 hours. The supernatants were harvested and stored at $-20{ }^{\circ} \mathrm{C}$ until required for assay by sandwich ELISA, whereas the cell pelletswere harvested, lysed then total proteins were resolved by SDS-PAGE followed by plotting proteins using Western blotting technique.

\subsection{Regulatory Effect of Probiotics}

To investigate probiotic regulation of macrophage cytokineproduction and STAT-3 activation, heat killed LcS (HK-LcS) or (HK-LF)were added in culture to final concentrations of $3 \times 10^{8}$ bacterial cells $/ \mathrm{ml}$, as a pretreatment for 6 hours prior to cytokine stimulation (either TNF- $\alpha$ or IL$1 \beta$ ) for a further 6hours in a humidified environmentat $37^{\circ} \mathrm{C}$, $5 \% \mathrm{CO}_{2}$ as described by Habil et al. (2011).

\subsection{Cytokine Measurement}

Macrophage cell production of the inflammatory cytokines, TNF $\alpha$ and IL-6, and anti-inflammatory cytokine IL-10 were analysed by sandwich ELISA using commercially available capture and detection antibodies from BDPharmingen (Oxford, UK). Protocols were performed based on methods ofHabil et al. (2014),colorimetric development was measured spectrophotometrically by an OPTIMax tuneable microplate reader at $450 \mathrm{~nm}$ and analysed by Softmax Pro version 2.4.1 software (Molecular Devices Corp., Sunnyvale, CA, USA).

\subsection{Statistical Analysis}

Statistical significance was analysed using a balanced analysis of variance (General Linear Model, Minitab version 16) followed by a multiple comparison test (LSD, least significant difference). Significance was set at $p<0.05$ $\left({ }^{*} \mathrm{p}<0.05, * * \mathrm{p}<0.01\right.$ and $\left.* * * \mathrm{p}<0.001\right)$.

\section{Results}

\subsection{Probiotic Bacteria Selectively Modulate Anti- Inflammatory Macrophage Cell Cytokine Production}

Stimulation anti-inflammatory macrophages by TNF- $\alpha$ or IL-1 $\beta$ was successfully inducing significant level of TNF- $\alpha$, IL-6 and IL-10 (Figure 1). Treatments of stimulated antiinflammatory macrophages with HK-LcS or HK-LF showed that probiotic treatments selectively modulated antiinflammatory macrophage cytokine production of TNF- $\alpha$, IL6 and IL-10. Results showed that HK-LcS suppressed TNFasignals by $26 \%$, whereas HK-LF augmented TNFasignalling by $49 \%$, resulting in modulation of $\mathrm{TNF}-\alpha$ cytokine production of anti-inflammatory macrophages. Using IL- $1 \beta$ to induce TNF- $\alpha$, HK-LcS augmented IL-1 $\beta$ signalling by $44 \%$, and HK-LF suppressed it by $18 \%$ (Figure 1A). Multi-faced IL-6 macrophage cytokine production was significantly induced by TNF- $\alpha$ or IL- $1 \beta$ signals. HK-LcS or HK-LF expresses different signals in modulation of TNF- $\alpha$ or IL-1 $\beta$ resulting in modulation of IL- 6 macrophage cytokine production. HK-LcS augmented TNF- $\alpha$ signal by $72 \%$, while HK-LF suppressed TNF- $\alpha$ inducing IL- 6 by $111 \%$. Using IL$1 \beta$ to induce IL- 6 macrophage cytokine production, HK-LcS suppressed IL6 signalling by 59\%, whereas, HK-LF augmented it by $66 \%$ (Figure 1B).The anti-inflammatory cytokine IL-10 expression by anti-inflammatory macrophage was successfully induced by the signals of TNF- $\alpha$ or IL-1 $\beta$, and probiotic bacteria were selectively modulated these signals resulting in modulation of macrophage cytokine production. HK-LcSupregulated TNF- $\alpha$ signal by $50 \%$, whereas suppressed IL-1 $\beta$ signal by $14 \%$. In contrast, HKLcS suppressed IL- $1 \beta$ signal by $25 \%$, and HK-LF increased it by $10 \%$ resulting in modulation of macrophage IL-10 cytokine production (Figure 1C). 

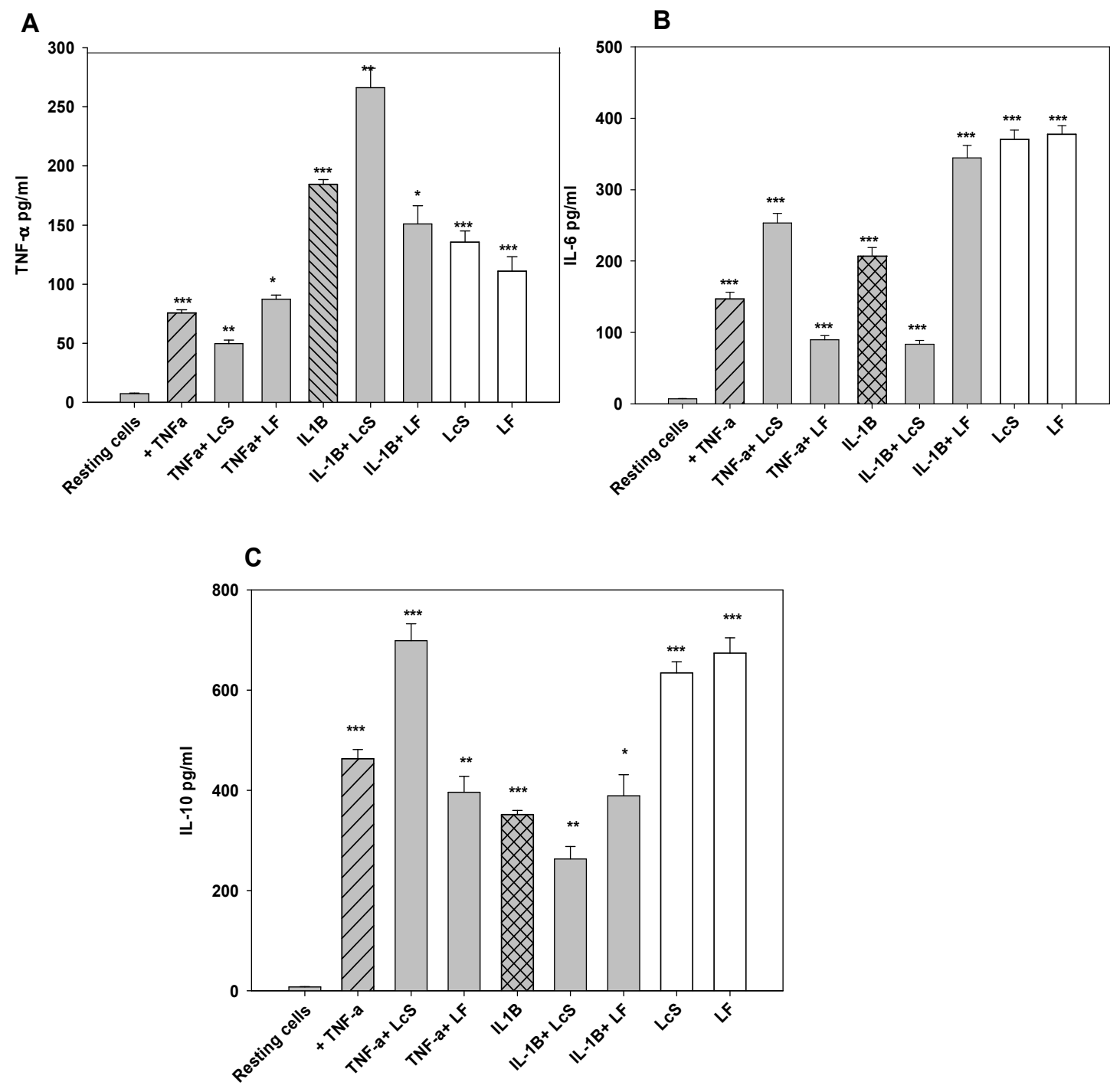

Figure (1). TNF- $\alpha$, IL-6 and IL-10 cytokine expression by anti-inflammatory macrophage cells differentially modulated by probiotic bacteria induced by TNF$\alpha$ or $I L-1 \beta$.

Anti-inflammatory macrophage cell M2s were pre-treated with heat killed (HK) of L.casie strain Shirota (LcS),or L.fermentum (LF) at cell concentration of $3 \times 10^{8} \mathrm{CFU} / \mathrm{ml}$ followed by stimulation with $5 \mathrm{ng} / \mathrm{ml}$ IL- $1 \beta$ or $10 \mathrm{ng} / \mathrm{ml} \mathrm{TNF}$ $\alpha$. Data representative of three independent experiments with triplicate sample. Significant value display as $\mathrm{P}<0.5 *$, $\mathrm{P}<0.01$ **, $\mathrm{P}<0.005$ ***.

\subsection{STAT-3 Activation Selectively Regulated by Probiotic Bacteria}

STAT-3 pathway is essential for IL-6 and IL-10 macrophage cytokine production. Stimulation macrophage cells with TNF- $\alpha$ or IL- $1 \beta$ were successfully activated STAT3 which correlated with cytokine production of IL-6 and IL10 (Figure 1,2).The selectively of probiotic activation of STAT-3 was clear, when LcSupregulated TNF- $\alpha$ signal leading to activate STAT-3 pathway (Figure 2), whereas LcS failed to activate IL-1 $\beta$ signal. HK-LF failed to activate signal of TNF- $\alpha$ or IL-1 $\beta$ related with STAT-3 activation (Figure 2). The modulation style of STAT-3 activation of anti-inflammatory macrophages by probiotic bacteria was depend on type of signal and type of probiotic bacteria. These results demonstrated that phosphorylation of STAT3 pathway was essential to IL-6 and IL-10 cytokine production of macrophages after stimulation by TNF- $\alpha$ or IL-1 $\beta$.

Full cell differentiated of anti-inflammatory macrophages were pre-treated with probiotic bacteria followed by stimulation with $5 \mathrm{ng} / \mathrm{mlIL}-1 \beta$ or $10 \mathrm{ng} / \mathrm{ml} \mathrm{TNF}-\alpha$. Cells lysed and cell lysates were analysed by SDS/PAGE and Western blotting using phospho- specific antibodies for STAT3 Tyr705 and an antibody that recognized the total STAT3. 


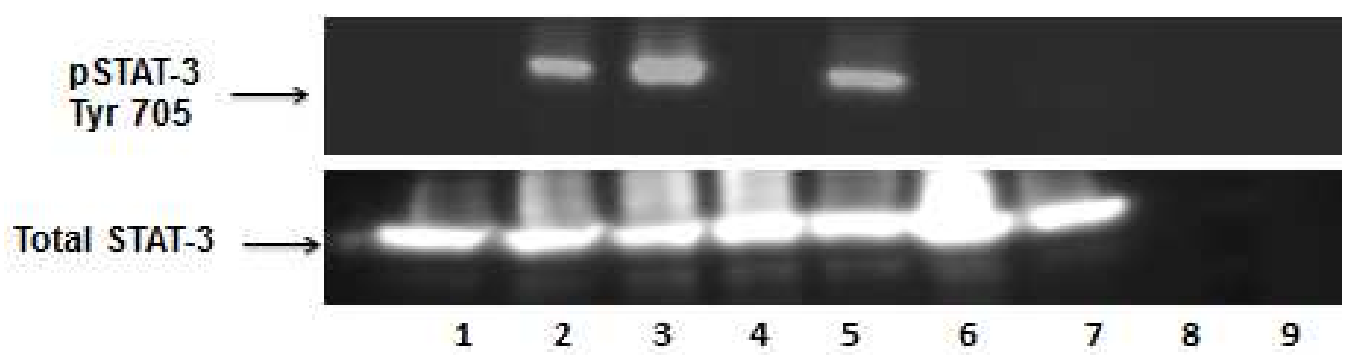

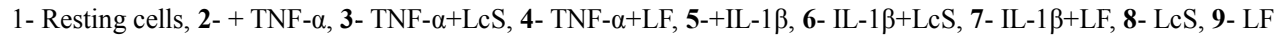

Figure (2). Probiotic stimulates phosphorylation of STAT-3 on Tyrosine 705 by macrophage cells.

\section{Discussion}

There is a general concept that STAT-3 is required to mediate the anti-inflammatory activity of IL-10 (Williams et al., 2004). STAT-3 is activated by phosphorylation at Tyrosine705, which induces dimerization, also further phosphorylation at site Serine 727 , followed by nuclear translocationand DNA binding(Darnell et al., 1994). Biethahn et al. (1999) reported that STAT-3have two isoform STAT-3a (86 kDa) and STAT-3b (79 kDa).O'Rourke and Shepherd (2002) demonstrated that transcriptional activation of STAT-3 was regulated by phosphorylation at Tyrosine 705 and Serine 727 in macrophages via the Mitogen-activated protein kinases(MAPKs). It is well documented that STAT-3 expression level depends on celltype, ligand exposure or maturation stage of the cells. Several reports highlighted that probiotics mediated anti-inflammatory activity through enhancement of IL-10 by macrophages (Steidler et al., 2000, Madsen et al., 2001, Galdeano and Perdigón, 2006, Shida et al., 2011, Habil et al., 2013). The present study demonstrates that IL-6 and IL-10 derived from anti-inflammatory macrophages are increased after treating induced macrophages with TNF- $\alpha$ by probiotic HK-LcS, which correlated with phosphorylation of STAT-3 transcriptional factor. It is well reportedthat STAT-3 mediates IL-10R signalling exerts anti-inflammatory activity by inhibiting proinflammatory cytokines such as TNF- $\alpha$ and IL-1 $\beta$ (Bromberg, 2002 , Williams et al., 2007, Williams et al., 2004). The STAT-3 signalling pathway is shared by IL-6 through gp130 a common signal transducer for the IL-6 cytokine (Fukada et al., 1996, Ahmed and Ivashkiv, 2000). IL-6/STAT-3 signals show a key role in the pathogenesis of IBD (Matsumoto et al., 2010, Matsumoto et al., 2005). IL-6 cytokine is one of the important cytokine mediated gut pathology especially in the setting of inflammatory bowel diseases (IBD) such as Crohn's disease (CD) and ulcerative colitis (UC). Many theories behind IBD pathology, and one of them is initiating the inflammation as a results of the interaction between antigen-presenting cells (APCs) and the local bacterial flora which contributes to an uncontrolled activation of mucosal $\mathrm{CD} 4^{+} \mathrm{T}$ lymphocytes called Th17. This type of $\mathrm{T}$ cells (Th17) described as high production of proinflammatory cytokines such as TNF- $\alpha$, IL-6, IL-12, IL-
23, IL-27(Harrington et al., 2005). It is well documented that both of $\mathrm{CD}$ and $\mathrm{UC}$ diseases, $\mathrm{CD} 4^{+} \mathrm{T}$ cells at the location of inflammation are vitally dependent on anti-apoptotic IL-6 signalling. By this means, IL-6 induces the transcription factor STAT-3 via trans-signalling (activation of a cell lacking membrane-bound IL-6 receptor via soluble IL-6 receptor)(Matsumoto et al., 2010). STAT-3 itself induces the anti-apoptotic factors bcl-2 and bcl-xL, thus resulting in Tcell resistance against apoptosis and become flooded with accumulated T cells (Fukada et al., 1996, Kovalovich et al., 2001). Therefore, the build-up of the nasty circle of Tcells mediated by apoptosis resistance was leading to chronic inflammation, which can be inhibited by down-regulation of IL-6 receptor. Anti-inflammatoryIL-10 cytokine production was upregulated by HK-LcS correlated with phosphorylation of STAT- 3 when macrophages stimulated with TNF- $\alpha$ only. These novel results showed that HK-LcS was drive phosphorylation of STAT-3 for TNF- $\alpha$ not for IL- $1 \beta$ signal. HK-LF treatment augmented TNF- $\alpha$ macrophage cytokine production induced by TNF- $\alpha$. It seems to be that lipoteichoic acids (LTA) from HK-LF which consider as one of the important member of the Lactobacillus family is the main cause for inducing pro-inflammatory cytokines by macrophage cells via NF-KB activation(Matsuguchi et al., 2003). Data suggest that probiotic bacteria drive proinflammatory process via activation of NF-KB resulting in inducing proinflammatory cytokines such as TNF- $\alpha$ and IL-6(Matsuguchi et al., 2003), on the other hand, probiotic drive anti-inflammatory process via activation the phosphorylation of STAT-3 pathway resulting in inducing anti-inflammatory cytokines such as IL-10 and suppressing the proinflammatory cytokine such as TNF- $\alpha$ (Matsumoto et al., 2005, Kim et al., 2006). It seems to be that the complex of polysaccharide-peptidoglycan (PSPG) in the bacterial cell wallof HK-LcS was mediated the anti-inflammatory process (Matsumoto et al., 2009).The results of this study provide good opportunity to inhibit IL-6 produced by macrophages activated by TNF- $\alpha$ or IL-1 $\beta$ by inhibiting the phosphorylation of STAT-3 leading to inhibit the gut inflammation. However, Matsukawa et al. (2005) reported that STAT-3 function as a repressor protein in resident macrophages. In conclusion, there is a specific structure on the probiotic bacteria cell wall plays a crucial role in controlling either proinflammatory or anti-inflammatory 
process via activation of NF-KB or STAT-3, therefore choosing specific probiotic strain in probiotic treatment is very important to control inflammation and treating the diseases related with cytokine production and $\mathrm{T}$ cell apoptosis.

\section{References}

[1] AHMED, S. T. \& IVASHKIV, L. B. 2000. Inhibition of IL-6 and IL-10 Signaling and Stat Activation by Inflammatory and Stress Pathways. The Journal of Immunology, 165, 5227-5237.

[2] AKHTAR, M., WATSON, J. L., NAZLI, A. \& MCKAY, D. M. 2003. Bacterial DNA evokes epithelial IL-8 production by a MAPK-dependent, NF-[kappa]B-independent pathway. FASEB J., 17, 1319-1321.

[3] BIETHAHN, S., ALVES, F., WILDE, S., HIDDEMANN, W. \& SPIEKERMANN, K. 1999. Expression of granulocyte colony-stimulating factor- and granulocyte-macrophage colony-stimulating factor-associated signal transduction proteins of the JAK/STAT pathway in normal granulopoiesis and in blast cells of acute myelogenous leukemia. Experimental hematology, 27, 885-894.

[4] BROMBERG, J. 2002 Stat proteins and oncogenesis. J Clin Invest. :, 09(9), 1139-1142.

[5] BUECHLER, C., RITTER, M., ORSÓ, E., LANGMANN, T., KLUCKEN, J. \& SCHMITZ, G. 2000. Regulation of scavenger receptor CD163 expression in human monocytes and macrophages by pro- and antiinflammatory stimuli. Journal of Leukocyte Biology, 67, 97-103.

[6] CHENG, F., WANG, H.-W., CUENCA, A., HUANG, M., GHANSAH, T., BRAYER, J., KERR, W. G., TAKEDA, K., AKIRA, S., SCHOENBERGER, S. P., YU, H., JOVE, R. \& SOTOMAYOR, E. M. 2003. A Critical Role for Stat3 Signaling in Immune Tolerance. Immunity, 19, 425-436.

[7] DARNELL, J., KERR, I. \& STARK, G. 1994. Jak-STAT pathways and transcriptional activation in response to IFNs and other extracellular signaling proteins. Science, 264, 14151421 .

[8] DONNELLY, R., DICKENSHEETS, H. \& FINBLOOM, D. 1999. The interleukin-10 signal transduction pathway and regulation of gene expression in mononuclear phagocytes. $J$ Interferon Cytokine Res, 19(6), 563-73.

[9] DOTAN, I. \& RACHMILEWITZ, D. 2005. Probiotics in inflammatory bowel disease: possible mechanisms of action. Current Opinion in Gastroenterology, 21, 426-430.

[10] DUFFIELD, J. S. 2003. The inflammatory macrophage: a story of Jekyll and Hyde. Clin. Sci., 104, 27-38.

[11] FOEY, A. 2012. Mucosal macrophages: phenotype and functionality in homeostasis and pathology. In. Handbook of macrophages: life cycle, functions and diseases. $E d s$. Takahashi, R. and Kai, H. Nova Science Publishers Inc., NY, USA. Invited review chapter.

[12] FUKADA, T., HIBI, M., YAMANAKA, Y., TAKAHASHITEZUKA, M., FUJITANI, Y., YAMAGUCHI, T., NAKAJIMA, K. \& HIRANO, T. 1996. Two Signals Are Necessary for Cell Proliferation Induced by a Cytokine Receptor gp130: Involvement of STAT3 in Anti-Apoptosis.
Immunity, 5, 449-460.

[13] GAldeAnO, C. M. \& PERDigÓN, G. 2006. The Probiotic Bacterium Lactobacillus casei Induces Activation of the Gut Mucosal Immune System through Innate Immunity. Clinical and Vaccine Immunology, 13, 219-226.

[14] GORDON, S. 2003. Alternative activation of macrophages. Nat Rev Immunol, 3, 23-35.

[15] GRIVENNIKOV, S., KARIN, E., TERZIC, J., MUCIDA, D., YU, G., VALLABHAPURAPU, S., SCHELLER, J., ROSEJOHN, S., CHEROUTRE, H., ECKMANN, L. \& KARIN, M. 2009. IL-6 and STAT3 are required for survival of intestinal epithelial cells and development of colitis associated cancer. Cancer Cell, 3; 15(2), 103-113.

[16] HABIL, N., ABATE, W., BEAL, J. \& FOEY, A. D. 2014. Heat-killed probiotic bacteria differentially regulate colonic epithelial cell production of human $\beta$-defensin-2: dependence on inflammatory cytokines. Beneficial Microbes, 5, 483-495.

[17] HABIL, N., BEAL, J. \& FOEY, A. 2011. Probiotic bacterial strains differentially modulate macrophage cytokine in a strain-depent and cell subset-specific manner. Beneficial Microbe, 2(4), 283-293.

[18] HABIL, N., BEAL, J. \& FOEY, A. 2012. Lactobacillus casei strain Shirota selectively modulates macrophage subset cytokine production. Int. J. Probiotics \& Prebiotics 7(1), 1-12.

[19] HABIL, N., FOEY, A. \& BEAL, J. 2013. Probiotic Modulation of Mucosal Immune Responses in an In Vitro CoCulture Model.

[20] HALLER, D., BODE, C., HAMMES, W. P., PFEIFER, A. M. A., SCHIFFRIN, E. J. \& BLUM, S. 2000. Non-pathogenic bacteria elicit a differential cytokine response by intestinal epithelial cell/leucocyte co-cultures. Gut, 47, 79-87.

[21] HARRINGTON, L. E., HATTON, R. D., MANGAN, P. R., TURNER, H., MURPHY, T. L., MURPHY, K. M. \& WEAVER, C. T. 2005. Interleukin 17-producing CD4+ effector $\mathrm{T}$ cells develop via a lineage distinct from the $\mathrm{T}$ helper type 1 and 2 lineages. Nat Immunol, 6, 1123-1132.

[22] HUME, D. A. 2006. The mononuclear phagocyte system. Current Opinion in Immunology, 18, 49-53.

[23] KIM, S. O., SHEIKH, H. I., HA, S.-D., MARTINS, A. \& REID, G. 2006. G-CSF-mediated inhibition of JNK is a key mechanism for Lactobacillus rhamnosus-induced suppression of TNF production in macrophages. Cellular Microbiology, 8, 1958-1971.

[24] KOVALOVICH, K., LI, W., DEANGELIS, R., GREENBAUM, L. E., CILIBERTO, G. \& TAUB, R. 2001. Interleukin-6 Protects against Fas-mediated Death by Establishing a Critical Level of Anti-apoptotic Hepatic Proteins FLIP, Bcl-2, and Bcl-xL. Journal of Biological Chemistry, 276, 26605-26613.

[25] MADSEN, K., CORNISH, A., SOPER, P., MCKAIGNEY, C., JIJON, H., YACHIMEC, C., DOYLE, J., JEWELL, L. \& DE SIMONE, C. 2001. Probiotic Bacteria Enhance Murine and Human Intestinal Epithelial Barrier Function. Gastroenterology, 121, 580-591.

[26] MANTOVANI, A., SICA, A. \& LOCATI, M. 2007. New vistas on macrophage differentiation and activation. European Journal of Immunology, 37, 14-16. 
[27] MATSUGUCHI, T., TAKAGI, A., MATSUZAKI, T., NAGAOKA, M., ISHIKAWA, K., YOKOKURA, T. \& YOSHIKAI, Y. 2003. Lipoteichoic Acids from Lactobacillus Strains Elicit Strong Tumor Necrosis Factor Alpha-Inducing Activities in Macrophages through Toll-Like Receptor 2. Clinical and Diagnostic Laboratory Immunology, 10, 259-266.

[28] MATSUKAWA, A., KUDO, S., MAEDA, T., NUMATA, K., WATANABE, H., TAKEDA, K., AKIRA, S. \& ITO, T. 2005. Stat3 in Resident Macrophages as a Repressor Protein of Inflammatory Response. The Journal of Immunology, 175, 3354-3359.

[29] MATSUMOTO, S., HARA, T., HORI, T., MITSUYAMA, K., NAGAOKA, M., TOMIYASU, N., SUZUKI, A. \& SATA, M. 2005. Probiotic Lactobacillus-induced improvement in murine chronic inflammatory bowel disease is associated with the down-regulation of pro-inflammatory cytokines in lamina propria mononuclear cells. Clinical \& Experimental Immunology, 140, 417-426.

[30] MATSUMOTO, S., HARA, T., MITSUYAMA, K., YAMAMOTO, M., TSURUTA, O., SATA, M., SCHELLER, J., ROSE-JOHN, S., KADO, S.-I. \& TAKADA, T. 2010. Essential Roles of IL-6 Trans-Signaling in Colonic Epithelial Cells, Induced by the IL-6/Soluble IL-6 Receptor Derived from Lamina Propria Macrophages, on the Development of Colitis-Associated Premalignant Cancer in a Murine Model. The Journal of Immunology, 184, 1543-1551.

[31] MATSUMOTO, S., HARA, T., NAGAOKA, M., MIKE, A., MITSUYAMA, K., SAKO, T., YAMAMOTO, M., KADO, S. \& TAKADA, T. 2009. A component of polysaccharide peptidoglycan complex on Lactobacillus induced an improvement of murine model of inflammatory bowel disease and colitis-associated cancer. Immunology, 128, e170-e180.

[32] MOSSER, D. M. \& EDWARDS, J. P. 2008. Exploring the full spectrum of macrophage activation. Nat Rev Immunol, 8, 958969.

[33] O'ROURKE, L. \& SHEPHERD, P. R. 2002. Biphasic regulation of extracellular-signal-regulated protein kinase by leptin in macrophages: role in regulating STAT3 Ser727 phosphorylation and DNA binding. Biochem. J., 364, 875-879.

[34] PAOLILLO, R., ROMANO CARRATELLI, C., SORRENTINO, S., MAZZOLA, N. \& RIZZO, A. 2009. Immunomodulatory effects of Lactobacillus plantarum on human colon cancer cells. International Immunopharmacology, 9, 1265-1271.

[35] SAVVIDOU, S. 2009. Selection of a chicken Lactobacillus strain with probiotic properties and its application in poultry production. . PhD thesis, University of Plymouth, Plymouth, $U K$.

[36] SHIDA, K., NANNO, M. \& NAGATA, S. 2011. Flexible cytokine production by macrophages and $\mathrm{T}$ cells in response to probiotic bacteria: A possible mechanism by which probiotics exert multifunctional immune regulatory activities. Gut Microbes, 2, 109-114.

[37] STEIDLER, L., HANS, W., SCHOTTE, L., NEIRYNCK, S., OBERMEIER, F., FALK, W., FIERS, W. \& REMAUT, E. 2000. Treatment of Murine Colitis by Lactococcus lactis Secreting Interleukin-10. Science, 289, 1352-1355.

[38] TAKEDA, K., CLAUSEN, B. E., KAISHO, T., TSUJIMURA, T., TERADA, N., FÖRSTER, I. \& AKIRA, S. 1999. Enhanced Th1 Activity and Development of Chronic Enterocolitis in Mice Devoid of Stat3 in Macrophages and Neutrophils. Immunity, 10, 39-49.

[39] VERRECK, F. A. W., DE BOER, T., LANGENBERG, D. M. L., HOEVE, M. A., KRAMER, M., VAISBERG, E., KASTELEIN, R., KOLK, A., DE WAAL-MALEFYT, R. \& OTTENHOFF, T. H. M. 2004. Human IL-23-producing type 1 macrophages promote but IL-10-producing type 2 macrophages subvert immunity to (myco)bacteria. Proceedings of the National Academy of Sciences of the United States of America, 101, 4560-4565.

[40] WILLIAMS, L., BRADLEY, L., SMITH, A. \& FOXWELL, B 2004. Signal Transducer and Activator of Transcription 3 Is the Dominant Mediator of the Anti-Inflammatory Effects of IL-10 in Human Macrophages. The Journal of Immunology, $172,567-576$.

[41] WILLIAMS, L. M., SARMA, U., WILLETS, K., SMALLIE, T., BRENNAN, F. \& FOXWELL, B. M. J. 2007. Expression of Constitutively Active STAT3 Can Replicate the Cytokinesuppressive Activity of Interleukin-10 in Human Primary Macrophages. Journal of Biological Chemistry, 282, 69656975.

[42] WINKLER, P., GHADIMI, D., SCHREZENMEIR, J. \& KRAEHENBUHL, J.-P. 2007. Molecular and Cellular Basis of Microflora-Host Interactions. J. Nutr., 137, 756S-772.

[43] YANG, J., LIAO, X., AGARWAL, M. K., BARNES, L., AURON, P. E. \& STARK, G. R. 2007. Unphosphorylated STAT3 accumulates in response to IL-6 and activates transcription by binding to NFkappaB. Genes \& development, 21, 1396-1408. 